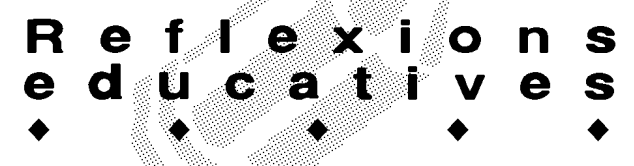

\title{
LA HISTÒRIA DE L'EDUCACIÓ A LA PROVÍNCIA DE TARRAGONA. POSSIBILITATS D'ESTUDI A PARTIR DEL FONS DEL GOVERN CIVIL DE L'ARXIU HISTÒRIC DE TARRAGONA
}

\author{
Antoni Gavaldà Torrents. Àrea de Didàctica de les Ciències socials. URV \\ Josep M.T. Grau. Arxiu Històric de Tarragona
}

Tradicionalment els estudis sobre la història de l'educació s'han escrit a partir de monografies d'institucions escolars, sovint aprofitant un aniversari o per la circumstància de canviar d'escola o de construir-ne una de nova. En general, hi ha hagut un condicionant que no ha ajudat gaire a presentar estudis seriosos, definitius, $\mathrm{i}$ és la conservació de la documentació, la qual pel fet d'estar fragmentada ha prefigurat uns determinats resultats. Aquesta circumstància ha comportat que hagin aparegut estudis reeixits i d'altres no tant, parcel.lats, de la vida escolar de determinades poblacions, mancats d'encaix en el context educatiu del país. Entre aquests darrers n'hi ha hagut de poc imaginatius, aïllant l'espai escolar de l'espai social i cultural, sense veure-hi les múltiples relacions que hi havia amb escreix i que donen sentit a una recerca de qualitat. En d'altres casos s'ha abusat de presentar un relat visual ampli, amb un cert regust positivista, descriptiu, mostrant una anàlisi del tot superficial de l'escola local, obviant l'aportació global d'aquesta en el camp social, la qual podria ser exemplificada per les peripècies per aconseguir la construcció escolar, o bé per la implicació dels mestres per la població on van passar, per citar-ne uns exemples il-lustratius. Altres vegades els estudis s'han abordat des de l'anàlisi dels llibres de text, o per la presentació descriptiva de llibretes escolars dels alumnes en un període concret, o en la divulgació de plànols de l'escola vella, etc. Per altra part, la investigació del paper del mestre en els aspectes psicopedagògics i, si és el cas, políticosindicals, ha tingut també escassa atenció, fet que sorprèn en aquest darrer estadi, ja que la seva figura, ultrapassant l'àmbit merament docent, formava part de la trilogia de poder patent i latent de la població, juntament amb el rector i el metge-apotecari. Alguns, val a dir-ho, han resultat meritoris.

La riquesa associativa del segle $X X$, lligada a les llibertats o prohibicions governamentals, ens ofereix pos- sibilitats per aprofundir en l'estudi del col-lectiu docent, i per extensió, en tot allò relacionat amb l'escola. D'aquest fet surten moltes opcions per treballar en temàtica d'història de l'educació que ultrapassin el perfil de l'anècdota i de la relació de mestres o d'alumnes, en llistats que condueixen a ben poc. Com a temes de treball podrien citar-se, sense ànim d'exhaustivitat, l'organització dels alumnes i pares per aconseguir, per millorar o per mantenir una escola en condicions; la cobertura social dels mestres i alumnes a càrrec de les mutualitats escolars; la sindicació o no del personal docent i la seva incidència a la societat; la demanda i el suport al fenomen de l'organització de les colònies escolars dels alumnes, promogudes pels ajuntaments; la persistent demanda per la consecució de l'estatus econòmic del mestre; la pugna entre l'escola nacional i l'escola religiosa; la relació epistolar entre mestres sobre temes acadèmics; la incidència efectiva dels plans d'estudi en la formació inicial dels mestres; la preparació de les sortides per a l'estudi del medi social i natural i els seus resultats; la potència $i$ adequació dels plans de reciclatge del professorat per a una formació continuada; el perfil dels periòdics escolars, realitzats pels alumnes sols o fets conjuntament per mestres, pares i alumnes; etc. Alguns d'aquests treballs, en l'àmbit d'escola concreta són definits, mentre que en altres casos encara en sabem poc, i es nota a faltar un emmarcament de tot el que ha representat l'escola primària al conjunt provincial i del país.

Amb aquest bagatge adjuntem tot seguit dos aspectes. Un, l'esment de tesines, llibres i articles publicats referits a la província de Tarragona, i segonament, les accions de possibles recerques en la font primària del que es conserva a l'Arxiu Històric de Tarragona (AHT).

\section{Bibliografia publicada per a una història de l'educació tarragonina}

Breument, i sense parar esment a les obres generals 


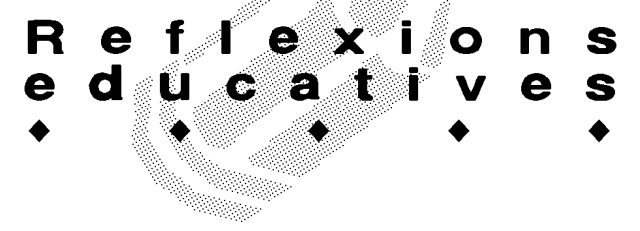

i a les monografies de municipis o de cooperatives, on sovint hi ha un capítol o apartat dedicat a l'ensenyament, hauríem de citar com a aportacions els llibres i articles següents, publicats a partir de la dècada dels vuitanta, referits a la província, dividits en cinc grans blocs, que es relacionen a l'apartat de bibliografia: 1) Treballs de recerca en format de tesina de llicenciatura. 2) Estudis que aborden la filosofia de determinats models d'escola. 3) Estudis concrets d'escoles. 4) Estudis d'institucions d'ajuda a l'escola. 5) Estudis biogràfics i autobiogràfics de mestres.

\section{Material de l'Arxiu Històric de Tarragona referit a temàtica educativa provinent del Fons del Govern Civil (sèrie d'Associacions)}

L'AHT guarda, provinent del fons de l'antic Govern Civil, material divers de temàtica educativa. És el material oficial que per llei havia de presentar-se per poder posar en funcionament una entitat. fessió

Agrupacions en defensa dels interessos de la pro-

Els mestres, com altres col-lectius, s'agruparen per millorar el seu estatus i defensar els seus drets. El 1900 es fundà l'Associació del Magisteri de la província de Tarragona, formada per docents de l'escola pública. Amb posterioritat, en les dècades dels anys vint i trenta, sorgiren grups d'àmbit més reduït, per partits judicials, al Vendrell, Reus, Falset, Montblanc, Valls, Tortosa...

En els reglaments conservats hi llegim que la seva finalitat era el foment de l'educació i el progrés de l'ensenyament. Les activitats que portaven a terme eren diverses: conferències, exposicions pedagògiques, subscripció a revistes tècniques del sector -de l'Estat $i$ de l'estranger-, creació i manteniment d'una biblioteca professional especialitzada amb llibres provinents de donacions i compra, promoció de la solidaritat entre els associats, incoació i tramitació dels expedients de viduïtat i els de jubilació dels mestres, etc.

El 1929 trobem la "Asociación de maestros nacionales" del partit de Tortosa, la qual havia intentat, el 1922, sense èxit, tramitar al govern civil la legalització dels seus estatuts. Hem de remarcar que aquestes associacions de districte eren membres de l'“Asociación provincial”, integrada a la vegada dins I'“Asociación Nacional del Magisterio primario" amb seu a Madrid.

També el 1922 documentem l'existència d'una societat de professors de música "La Unión musical", i el 1935 la creació de la Federació Provincial de Treballadors de l'Ensenyament, adherida a la FETE, d'estructura sindical ugetista.

Associacions d'alumnes i exalumnes

Un altre grup d'entitats era el que conformaven els estudiants o antics alumnes, tant de centres d'ensenyament primari com de secundari, fossin de dependència pública o privada. A Tarragona ciutat, el 1926, trobem que es creà l'Associació d'exalumnes de l'“Instituto Nacional de Segunda Enseñanza”, encara activa en l'actualitat. Entre els seus objectius hi havia el de donar suport moral i material a la institució, fomentar els vincles d'amistat i l'establiment de beques o el pagament de matrícules als nois amb menor renda, a més de facilitarlos material d'estudi. També cooperaven en l'obra cultural de l'Institut amb l'organització de xerrades, cursets, excursions pedagògiques, etc. Els seus membres tenien dret a participar en les activitats i a utilitzar el laboratori i la biblioteca. Hem de fer esment de les agrupacions d'alumnes i exalumnes de les escoles del Treball de Reus, Tarragona, Tortosa i Valls, federades a nivell provincial. Hauríem de distingir les fundades durant la Segona República de les del franquisme.

A Tortosa el 1930 tenim notícia de l'existència de l'Associació d'Estudiants Cristians. En aquesta línia hem de destacar a Tarragona l'Associació d'Antics Alumnes d'Acció Popular Catòlica, el 1932. Aquestes entitats d'ideari cristià posaven atenció preferent a la formació religiosa, a més de les habituals de foment de la cultura, amb la celebració de certàmens i vetllades literàries, cinema, concerts, excursions i sortides, esport -futbol, gimnàstica-, folklore, etc. A Tarragona, el curs 19401941 i a Cambrils, el 1953, apareixen les d'antics alumnes de les escoles cristianes dels germans de la Salle.

Altrament, en les dècades dels anys setanta i vuitanta, proliferaren les associacions de pares d'alumnes.

\section{Les mútues escolars}

A la província de Tarragona, d'igual forma que a la resta de Catalunya, detectem la presència de mutualitats escolars. La mútua era una societat de socors mutus d'ajut en cas de malaltia o defunció, amb subsidis per pagar els salaris als metges per necessitat d'haver de visitar el mestre o l'alumne malalt, sufragar els medicaments de la malaltia i si de cas, les despeses d'enterrament. Moltes estaven vinculades a la Caixa de Pensions per a la Vellesa i d'Estalvis de Catalunya i Balears.

A l'AHT hi consten expedients de mútues del Priorat -Falset, Gratallops i Torroja-, del Baix Penedès -el Vendrell-, del Baix Camp -Reus i Vilanova d'Escornalbou-, de la Ribera d'Ebre-Móra d'Ebre-, del Tarragonès -la ciutat de Tarragona- i de l'Alt Camp -el Rourell-. Els noms amb què es designaven són diversos, des de literats catalans com Guimerà o Verdaguer, a personalitats locals, a més de genèrics com La Flor del Priorat, Cossetània o Lliçó de Nick. La majoria van ser creades en la dècada dels anys trenta del segle passat, a l'empara del Reial decret del Ministeri d'Instrucció Pública del 7 


\section{$R$ e f e e $x^{\prime}$ i n s \\ e d u c a ti v e s}

de juliol de 1911 i de la Llei d'assegurances i d'associacions del 1932.

En el reglament de la del Rourell llegim que s'admetien socis dels 3 als 18 anys, amb una quota de deu cèntims setmanals. Destacava l'obra social envers els xiquets, amb la realització de colònies, viatges escolars, campanyes de sensibilització contra l'alcoholisme i a favor de la higiene.

Els fons documentals poden completar-se en els arxius de les entitats financeres o bé a les mateixes escoles. Recentment l'Arxiu Nacional de Catalunya de Sant Cugat del Vallès ha ingressat el fons de la Mútua Escolar Blanquerna, de Barcelona.

Patronats escolars i Associacions de mares i pares d'alumnes

A l'AHT la documentació no és gaire abundant, i les entitats localitzades ho són a nivell local. El patronat era una institució creada per reglamentar i gestionar el funcionament de determinades escoles i per dirigir accions de defensa educativa a favor de grups d'alumnes, de treballadors d'un determinat ram o en temes en què l'Estat era poc sensible. De patronats, en trobem a Tortosa el 1920-1930, amb el nom de Patronat escolar obrer de la
Sagrada Família; a Reus, el 1931 per a la creació i sosteniment de l'escola catalana; a Sant Vicenç de Calders, el 1932 en format d'un Patronat escolar de la colònia ferroviària.

Les associacions de mares i pares d'alumnes, com el seu nom indica, eren formades per pares d'alumnes per ajudar els seus fills en activitats extraescolars, bàsicament de lleure. A l'AHT hi ha la de Montblanc, del 1932, com Amics de l'Escola, i a Gandesa el 1933 i a Poboleda el 1934, amb la denominació "Amigos de la enseñanza". També a Valls el 1932 es legalitzà l'Associació de pares i mares d'alumnes de les escoles nacionals. Hem de constatar que sempre fan referència a centres públics.

\section{Educació no formal}

Per educació no formal hauríem d'entendre la que no és reglada, o sigui la que no és oficial. A l'AHT hi consta documentació de Tortosa, del 1933, de quan es constituí l'Escola Dominical, amb l'objectiu de donar instrucció gratuïta a les dones treballadores, com podien ser les obreres o les minyones. A través dels comptes constatem les despeses ocasionades tant per la compra

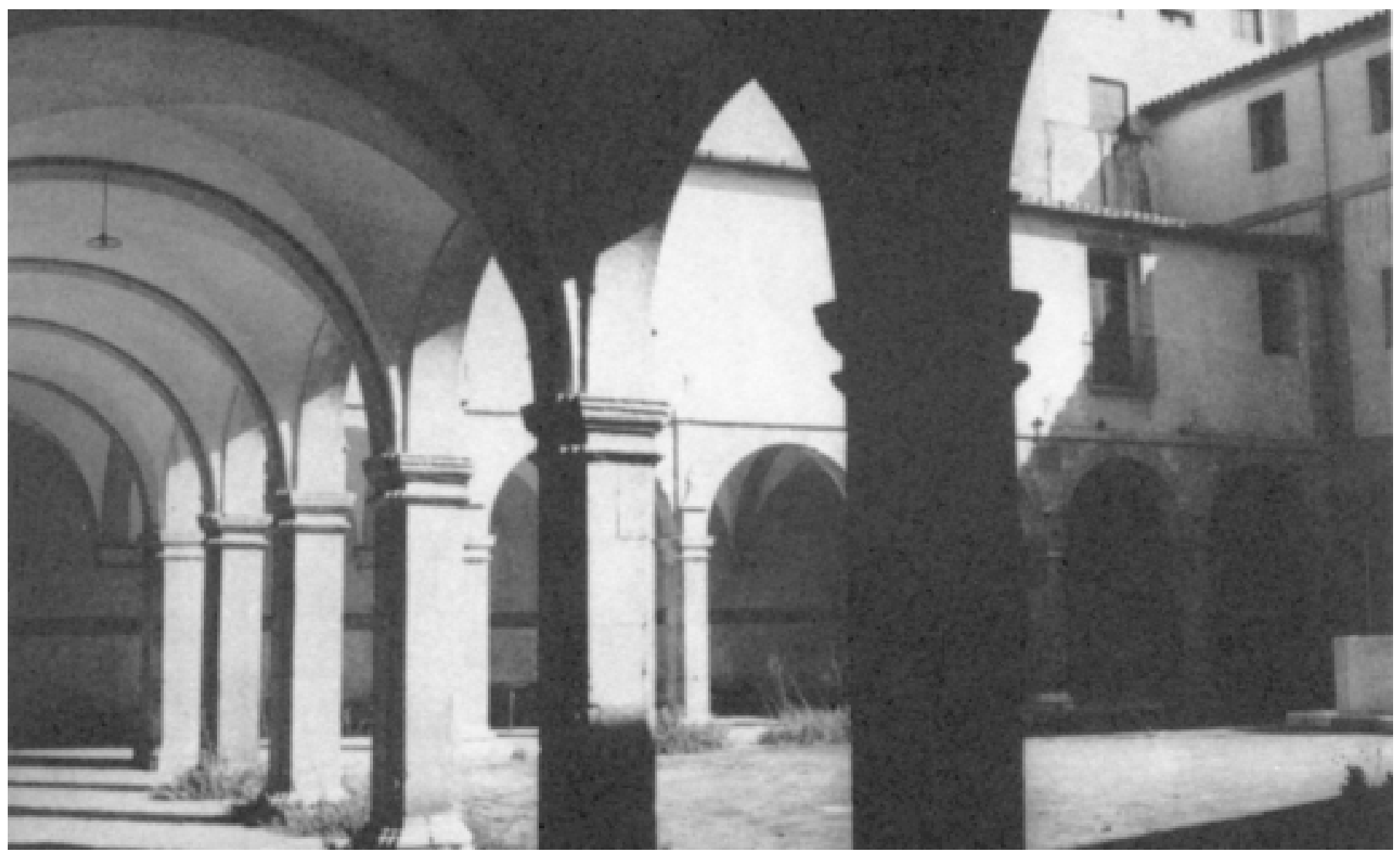

Primer edifici de I'“E.N. de maestros de Tarragona”, de 1843 a 1849, ubicada a l'antic convent de Sant Francesc 


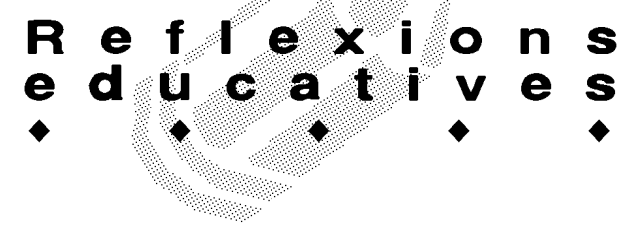

de material, salaris, els premis per a les alumnes o les despeses produïdes per les festes del Carnaval. Respecte de les acadèmies, es disposa de poques referències. A Tarragona ciutat l'AHT disposa d'un gruixut expedient, amb més d'un centenar de fulls, de l'Acadèmia de Taquigrafia -1946-1950-, en ple franquisme.

\section{Apunts per a possibles treballs}

Els expedients d'associacions que comentem solen constar principalment dels estatuts, l'acta fundacional, llistat de socis, balanços econòmics i notificacions de canvis de junta de govern. El seu buidatge és senzill i sovint repetitiu, ja que molts reglaments són semblants entre si. És fonamental fer un seguiment de l'entitat a través de la premsa de l'època, de la documentació municipal i de l'enquesta oral, ja que els noms que hi apareixen poden ser el punt de partida. Si encara hi ha testimonis vius, podran informar de la possible destinació de la documentació en el sentit de poder saber si es va perdre, si es va deixar a l'escola, a l'Ajuntament, a la parròquia o resta encara en mans particulars. Malauradament falta encara conèixer el contingut del fons històric de la Delegació Provincial del Ministeri d'Educació i Ciència a Tarragona, la qual, de ben segur, aportarà nous elements d'anàlisi i reflexió, complementaris del procés.

\section{Bibliografia}

Treballs de Recerca en Format de Tesina de Llicenciatura FERRER CELMA, F.; SAMPEDRO SÁNCHEZ, J. A.; SOLÉ VALLS, M. La enseñanza primaria, en la comarca del Baix Ebre, durante la Segunda República (1931-1936). Tesina. 1977.

FIGUERAS SERRANO, M. J. i TEIXIDÓ RIBERA, J. L'ensenyament a Tarragona (1931-1936). Tesina. 1981.

PALMA GONZÁLEZ, C. La obra pedagógica de Pablo Delclós en Tarragona. Tesina. 1982.

VIANA LLUCH, J. Panorámica cultural durante la I/ República. El ejemplo catalán como intento de creación de una democracia educacional. Tesina. 1977.

- Estudis que Aborden la Filosofia de Determinats MoDELS D'ESCOLA

CAVALLÉ I BUSQUETS, J. Teoria i realitat en el pla d'extensió de l'ensenyament primari de 1847 a la comarca del Baix Camp, a «Penell. Revista d'història», 1 (1984) 81-88. Reus.

GAVALDÀ TORRENTS, A. L'escola de la Societat Agrícola de Valls. Repàs d'un ensenyament encarat a les classes populars, a XXXV Assemblea Intercomarcal d'Estudiosos de Catalunya. Valls. Institut d'Estudis Vallencs. 1989. p. 293305.

GAVALDÀ TORRENTS, A. L'Escola Moderna de Valls 19091919, a XI Jornades d'Història de l'Educació als Països Catalans. Reus. Edicions del Centre de Lectura. 1992. p. 27-48.
GAVALDÀ TORRENTS, A. Els inicis de l'escola en temps de guerra al partit judicial de Valls, a Butlletí de la Societat Catalana d'Estudis Històrics. Barcelona. Institut d'Estudis Catalans. 2001. p. 53-84.

GRAS REVERTÉ, P. i JMÉNEZ GONZÁLEZ, J. M. L'ensenyament a la Canonja 1922-1936. Una perspectiva etnogràfica, a Treballs Canongins. La Canonja. Centre d'Estudis Canongins Ponç de Castellví. 1996. p. 33-128.

LARRAÑAGA CORTÉS, R. Les ideologies a la formació tècnica i professional vallenca 1904-1924, a «Cultura», 597 (1999) 7-9. Valls. AAEET.

NOGUERA ARROM, J. El català a l'Escola Normal de Tarragona abans del 1931. (Tres anècdotes referents a l'Escola Normal de Tarragona), a Actes de les 7es Jornades d'Història de l'Educació als Països Catalans (publicades a cura de Jordi Monés i Pere Solà). Eumo Editorial. Vic. 1985. p. 255-262.

NOGUERA ARROM, J. Escola i entorn. Un important precedent metodològic: les excursions pedagògiques del prof. Alexandre de Tudela, a L'educació al món urbà. 9es Jornades d'Història de l'Educació. Diputació de Barcelona. 1987. p. 64-76. - Estudis Concrets d'Escoles

BIOSCA i ESTEVE, T. Una aproximació a l'escola professional de Valls. El seu naixement. "Quaderns de Vilaniu. Miscel-lània de l'Alt Camp», 15 (1989) 39-61. Valls. Institut d'Estudis Vallencs.

BOFARULL MALAPEIRA, R. i SALVADÓ MUNTANÉ, J. L'escola pública a la Canonja (1845-1922), a Treballs Canongins. Centre d'Estudis Canongins. 1992. p. 21-76.

COMAS NOLLA, G. L'ensenyament a Torredembarra a començament de segle, a Recull de Treballs-2. Centre d'Estudis 'Sinibald de Mas'. Torredembarra. 1984. p. 35-44.

GAVALDÀ TORRENTS, A. i GAVALDÀ BATALLA, J. L'escola a l'inici de la guerra a poblacions del mig Gaià: Bràfim, Vilabella i Vila-rodona, a "La Resclosa», 4 (2000) 75-99. Ed. Centre d'Estudis del Gaià. Vila-rodona.

GAVALDÀ TORRENTS, A. i GAVALDÀ BATALLA, J. L'escola d'Alcover a l'esclat de la guerra del 1936, a "Butlletí del Centre d'Estudis Alcoverencs», 85 (2000) 34-55. Alcover.

GAVALDÀ TORRENTS, A. i GAVALDÀ BATALLA, J. L'escola de la Riba a l'inici de la guerra del 1936, a «El Brugent», 190 (2000) 14-17. Montblanc.

GINER FILELLA, R. Les Cases-col/legi teresianes a Tarragona. Els Ibanos. Tarragona. 1999. 93 p.

HUERTA HUERTA, L. L'ensenyament privat a Móra d'Ebre: 1. El Col/legi Santa Teresa, a «La Riuada», 13 (1998) 30-33.

MILÀ, J. L'ensenyament en una vila rural: el cas de la Selva del Camp entre 1874-1900, a Actes de les 7es Jornades d'Història de l'Educació als Països Catalans (publicades a cura de Jordi Monés i Pere Solà). Eumo Editorial. Vic. 1885. p. 401-417.

NOGUERA ARROM, J. La Escuela Normal de Tarragona (1843-1931). Cien años de la vida de una Escuela Normal. Publicacions i Edicions de la Universitat de Barcelona. Barcelona. 1984. 237 p.

PITARCH MORELL, M. T. L'Escola Mare de Déu de Misericòrdia: cent anys d'història (1899-1999). Col-legi Mare 


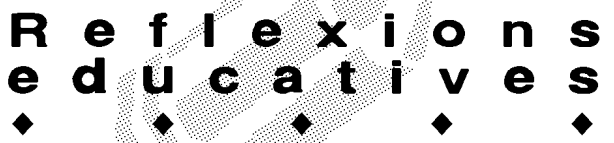

de Déu de la Misericòrdia. Reus. 1999. 259 p.

PITARCH MORELL, M. T. L'Institut Salvador Vilaseca de Reus. Fundació Roger de Belfort. Reus. 1999. 429 p.

PUYOL TORRES, C. L'ensenyament primari a Salou. Notícia de la primera escola 1888-1911, a «Estudis de Salou. Recull 1996», (1996) 63-90. Ajuntament de Salou.

- Estudis d'InstiTuCIONS d'AJUdA A L'Escola

ANGUERA i NOLLA, P. L'associació protectora de l'ensenyança catalana a Reus, a Actes de les 7es Jornades d'Història de l'Educació als Països Catalans (publicades a cura de Jordi Monés i Pere Solà). Eumo Editorial. Vic. 1985. p. 179-190.

COMES NOLLA, G. El Patronat Antoni Roig i l'ensenyament a Torredembarra (1886-1935). Ed. El Mèdol. Tarragona. 1992. $159 \mathrm{p}$.

Estudis de Processos Educatius d'Abast General

ANGUERA NOLLA, P. Materials per a la història de l'educació a Reus: 1810-1833, a $A$ bodes em convides. Publicacions del Centre de Lectura. Reus. 1987. p. 11-23.

ARNAVAT, A. Notes sobre l'ensenyament a Reus en el primer quart del segle $X X$, a Actes de les 7es Jornades d'Història de l'Educació als Països Catalans (publicades a cura de Jordi Monés i Pere Solà). Eumo Editorial. Vic. 1985. p. 367-377.

ARTACHO LABRADOS, N.; GARCÍA CAZORLA, C.; MUIÑOS VILLAVERDE, M. J. Aproximación al sistema educativo en Valls a través de la historia material, a Sisenes Jornades d'Història de l'Educació als Països Catalans. Escola Universitària de Magisteri. Lleida. 1984. p. 299-304.

CASAS i ROM, M. P. Municipis i escolarització. El cas de Cambrils (1974-1987), a L'educació al món urbà. IX Jornades d'Història de l'Educació. Diputació de Barcelona. 1987. p. 64-76.

CASAS i ROM, M. P. Analfabetisme, escolarització i processos d'educació no formal a Cambrils: 1960-1990, a XI Jornades d'Història de l'Educació als Països Catalans. Edicions del Centre de Lectura. Reus. 1992. p. 107-130.

CAVALLÉ i BUSQUETS J. L'impuls de l'ensenyament al Camp de Tarragona a mitjan segle XIX, a Quaderns d'Història Tarraconense VI. Institut d'Estudis Tarraconenses Ramon Berenguer IV. Tarragona. 1987. p. 87-100.

CENTRE D'ESTUDIS ALCOVERENCS. EQUIP D'HISTÒRIA DE L'ENSENYAMENT. L'ensenyament a Alcover: la història de l'educació des d'una perspectiva local. Centre d'Estudis Alcoverencs. Alcover. 1982. 217 p.

CORTS i SALVAT, J. R. L'educació a Riudoms a les acaballes de l'Antic Règim 1790-1847, a XI Jornades d'Història de l'Educació als Països Catalans. Edicions del Centre de Lectura. Reus. 1992. p. 49-61.

DUCH i PLANA, M. L'educació en el medi rural durant la Restauració: Constantí (1874-1924), a Sisenes Jornades d'Història de l'Educació als Països Catalans. Escola Universitària de Magisteri. Lleida. 1984. p. 186-199.

FERRER i BOSCH, M. A. L'educació a Tarragona durant el Trienni Constitucional (1820-1823), a Quaderns d'Història Tarraconense /I. Institut d'Estudis Tarraconenses Ramon Berenguer IV. Tarrragona. 1980. p.135-154

GRAU VERGE, F. i VISCARRO GAUXACHS, M.C. L'en- senyament a Ulldecona: de la crisi del 98 a la Guerra Civil, a «Raïls. Butlletí del Centre d'Estudis d'Ulldecona», 8 (1996) 33-69.

GAVALDÀ TORRENTS, A. Les colònies iles semicolònies escolars, a Valls, durant la segona República. Les concepcions ideològiques. L'organització teòrico-pràctica i els seus resultats, a Quaderns de Vilaniu. Miscel/lània de l'Alt Camp. 16. Institut d'Estudis Vallencs. Valls. 1989. p. 3-33.

GORT i JUANPERE, E. L'ensenyament al Camp de Tarragona a l'edat mitjana, a XI Jornades d'Història de l'Educació als Països Catalans. Edicions del Centre de Lectura. Reus. 1992. p. 15-24.

GRAU PUJOL, J. M. i PUIG TÀRRECH, R. Instrucció pública i alfabetització a Montblanc en el segle XVIII, a Aplec de treballs del Centre d'Estudis de la Conca de Barberà, 8. Montblanc.1987. p. 111-141.

JORDÀ i FERNÁNDEZ, A. Ensenyament i educació a Tarragona: les ordenances municipals de 1911, a XI Jornades d'Historia de l'Educació als Països Catalans. Edicions del Centre de Lectura. Reus. 1992. p. 97-106.

La Riuada. Revista d'informació cultural. Núm. 13. Monogràfic: L'ensenyament a Móra 1939-1988. Móra d'Ebre. Ribera d'Ebre. 1998. 64 p. (Conté articles de J. Solé Arnal, J.Montfort Tena, M.S. Pérez, A. Cot, L. Huerta Huerta, M. Coll i J. M. Solé Poll, entre d'altres).

TARRÒS ESPLUGAS, R. De l'ensenyament secundari a Reus: antecedents immediats de l'Institut de $2 n$ Ensenyament, a XI Jornades d'Història de l'Educació als Països Catalans. Edicions del Centre de Lectura. Reus. 1992. p. 63-79.

TARRÒS ESPLUGAS, R. Els escolapis a Valls, a XI Jornades d'Història de l'Educació als Països Catalans. Edicions del Centre de Lectura. Reus. p. 82-95.

VÁZQUEZ PRADA, M.T. Situació de l'ensenyança a Tarragona, a Sisenes Jornades d'Història de l'Educació als Països Catalans. Escola Universitària de Magisteri. Lleida. 1984. p. 401-415.

- Estudis Biogràfics I Autobiogràfics de Mestres

ARTIGA I ESPLUGAS, C. L'escola que jo he viscut (19191977). Ed. Germans Palacín Artiga. Reus. 1991.

BAIXERAS i SASTRE, E. El mestre Pau Delclòs (18651942), a Recull Pau Delclòs i Dols (1865-1942). Estació de Recerca Bibliogràfica i Documental "Margalló del Balcó". Tarragona. p. 10-32.

COMAS RUBÍ, F. i MIRÓ MONTOLIU, M. I. Rosa Roig biografia d'una pedagoga, 1890-1969. Ed. El Mèdol. Tarragona. 2001.

MATA i GARRIGA, M. Àngels Garriga, la seva escola, la seva generació de mestres. Ed. Fundació Àngels Garriga de Mata. Saifores. 1998. $31 \mathrm{p}$.

VÁZQUEZ PRADA, M.T. Contribucions de Pau Delclós a la renovació pedagògica del nucli urbà tarragoní, a L'educació al món urbà. IX Jornades d'Història de l'Educació. Diputació de Barcelona. 1987. p. 447-457. 